\title{
Ueber den blauen Farbstoff aus den Flossen des Crenilabrus pavo.
}

\author{
II. Mittheilung. ${ }^{1}$ ) \\ Von
}

Dr. Rich. v. Zeynek.

(Aus der K. K. zoologischen Station in Triest und dem Universitäts-Laboratorium für medicinische Chemie in Wien.)

(Der Redaction zugegangen am 26. September 1902.)

Crenilabrus pavo wird ziemlich häufig in Exemplaren von 200-300 g Gewicht auf den Triester Fischmarkt gebracht. Er ist den grössten Theil des Jahres hindurch unscheinbar gelbgrün mit hellblauer Zeichnung gefärbt. Die Färbung rührt im Wesentlichen von den gelbgrünen Schuppen her, die unter dem Mikroskope schwarze Körnchen, anscheinend regellos vertheilt, spärliche rothe ölige Tropfen und in dem Maschwerke Körnchen eines sehr fein vertheilten, aber distinct von dem Gewebe gesonderten gelbgrünen Farbstoffes zeigen. Sowohl der rothe Farbstoff wie der gelbgrüne sind in Aether wie in Aceton löslich.

Im Frühjahr ändert sich die Farbe dieses Fisches in eine prächtig blaue (das sog. Hochzeitskleid). Besonders schön tritt diese an den beiden Seiten des Fisches, und zwar sowohl in den Schuppen, als auch in der Haut, ferner in den Flossen auf; nur die Kiemenflossen behalten ihre helle Färbung, während sogar ein Theil der Iris blau gefärbt ist, selbst das Fleisch und die Knochen einen hellblauen Farbenton annehmen. Die blaue Färbung der Schuppen und Flossen ist durch eine rothe Zeichnung unterbrochen. Bei etwa 300facher Vergrösserung stellt sich diese rothe Zeichnung als ein Haufwerk von fettartigen Tropfen dar, die blaue Farbe dagegen scheint das Gewebe ganz diffus zu durchdringen, es ist nirgends eine scharfe Abgrenzung des blauen Farbstoffes vom eigentlichen

1) Vergl. diese Zeitschr., Bd. XXXIV, S. 148. 
Gewebe, etwa in Form einer Einlagerung blauer Farbstoffkörner, wahrzunehmen.

Durch die Vermittlung des Directors der Triester zoologischen Station, Herrn Prof. Dr. C. Cori, dem ich für seine liebenswürdige Bemühung zu besonderem Danke verpflichtet bin, erhielt ich etwa $60 \mathrm{~kg}$ des schön gefärbten Fisches und konnte damit die Reindarstellung des blauen Farbstoffes versuchen.

Ich habe zuerst alle blaugefärbten Hautpartien vom anhaftenden Schleime durch rasches Abschwemmen mit Wasser befreit, hierauf mit Aceton extrahirt. Das Aceton löst den rothen Farbstoff und den durch die lebhaften Farben verdeckten, die Färbung des Fisches zu anderen Jahreszeiten bedingenden gelbgrünen Farbstoff auf, während der blaue Farbstoff ungelöst bleibt. Das erste, wasserhaltig gewordene Aceton wurde nach kurzer Einwirkung durch frisches ersetzt, und nach der Entwässerung wurde noch solange mit reinem, über Natrium destillirtem Aether gewaschen, bis der Aether nichts mehr aufnahm.

Vorversuche hatten ergeben, dass der blaue Farbstoff von destillirtem Wasser gelöst wird; noch rascher erfolgt die Lösung desselben in Wasser nach der Aceton-Aetherextraction. Diese Lösungen zeigten auch bei weiterer Verdünnung mit Wasser keine Fällung und keine Aenderung des charakteristischen Absorptionsstreifens im rothen Theile des Spectrums, sodass das seinerzeit beschriebene Verhalten auf eine Veränderung des Farbstoffs in der Glycerinlösung, wahrscheinlicher aber auf die Gegenwart von Verunreinigungen zurückzuführen wäre. Die weitere Verarbeitung der wässerigen Lösungen machte grosse Schwierigkeiten, da sie sehr unrein waren, zudem rasch Fäulniss unter Zersetzung des Farbstoffes eintrat. Nach mehreren vergeblichen Versuchen habe ich von der Verwendung der Schuppen und der Haut abgesehen und lediglich die Flossen zur Darstellung des Farbstoffes verwendet. Diese wurden also systematisch mit Aceton und Aether behandelt und der rein blaue Rückstand mit destillirtem Wasser übergossen. Die Wasserextraction wurde nicht lange fort- 
gesetzt, um zu verhüten, dass bei anhaltender Maceration andere, nicht färbende Substanzen in Lösung gingen, und es wurde nur das erste, rasch gewonnene Extract verarbeitet. Aus den noch immer hellblau gefärbten Rückständen liess sich noch ein blau gefärbter Auszug mit Wasser herstellen, der das charakteristische spectrale Verhalten zeigte und sich gegen Reagentien ebenso wie der erste Auszug verhielt, sodass kein Grund zur Annahme vorliegt, die restliche Färbung der Flossen komme einem anderen als dem untersuchten blauen Farbstoff zu.

Die tiefblauen wässerigen Lösungen waren gut filtrirbar, mit einiger Sorgfalt gelang es, bei der weiteren Verarbeitung ihre Fäulniss $\mathrm{zu}$ verhüten. In die klaren blauen Lösungen wurde $10 \%$ Ammonsulfat eingetragen, durch welches ein geringer, hellblauer Niederschlag entstand. $\mathrm{Zu}$ der von diesem Niederschlage filtrirten Flüssigkeit wurde noch 5\% Ammonsulfat zugefügt; durch dieses trat eine stärkere Trübung der Flüssigkeit ein, nach 36 Stunden hatte sich der fein vertheilte Niederschlag zu Boden gesenkt. In diesem Niederschlage war der färbende Stoff enthalten, die überstehende Flüssigkeit war nur ganz hellgrün gefärbt. Nach der Entfernung der Hauptmenge der überstehenden Lösung mit einem Heber wurde der Niederschlag mit Ammonsulfatlösung gewaschen. Auch durch dichte, gehärtete Filter liess sich der Niederschlag schlecht filtriren, nur durch wiederholtes Aufgiessen des Anfangs trüben Filtrates wurde der Niederschlag schliesslich auf dem Filter gesammelt. Durch Centrifugiren war ein vollständiges Absetzen auch nicht zu erzielen gewesen. Das Filtriren hatte mehrere Tage in Anspruch genommen.

Der Niederschlag löste sich zwar langsam, doch bis auf einen geringen, schleimigen, hellgrün gefärbten Rest vollständig in Wasser auf, seine filtrirte Lösung wurde gegen oft gewechseltes destillirtes Wasser dialysirt, bis im Dialysate mit Nessler'schem Reagens Ammoniak nicht mehr nachgewiesen werden konnte. Als Dialysator benützte ich ein tabaksbeutelartig zusammengefaltetes Pergamentpapier. Als einmal dis Wasser durch mehrere Tage nicht gewechselt worden war, 
war in dem Dialysate eine geringe Spur einer Blaufärbung zu beobachten.

Der Dialysirrückstand wurde von einem geringen, schleimigen Niederschlage filtrirt, hierauf bei Zimmertemperatur im Vacuum über Schwefelsäure eingedunstet. Es blieben tiefblaue, durchsichtige, amorphe, recht spröde Lamellen, die auch in festem Zustande das charakteristische Spectrum zeigten, zurück, die unter Aether sich zu einem feinen Pulver zerreiben liessen. Die Menge des so isolirten Farbstoffes betrug etwa 1,2 g.

Ursprünglich leicht in Wasser löslich, zeigte sich nach zweimonatigem Liegen eine Abnahme der Löslichkeit, wie sie etwa bei Blutfarbstoffpräparaten $\mathrm{zu}$ beobachten ist; doch löste sich der so veränderte Farbstoff nach einigem Zuwarten vollständig in Wasser. Gleichzeitig hatte das Präparat eine leichte Verfärbung ins Grüne angenommen.

Bei der Elementaranalyse wurden folgende Werthe für die bei $105^{\circ}$ getrocknete Substanz erhalten:

$0,2446 \mathrm{~g}$ Substanz gaben 0,1444 $\mathrm{g}$ Wasser und 0,4318 $\mathrm{g}$ Kohlensäure entsprechend 48,143\% Kohlenstoff und 6,559\% Wasserstoff.

$0,1133 \mathrm{~g}$ Substanz gaben nach Dumas mit Bleichromat unter vorgelegter Kupfer- und Kupferoxydschichte verbrannt $14,8 \mathrm{ccm}$ trockenen Stickstoff bei $22,6^{\circ}$ und $748 \mathrm{~mm}$ Quecksilberdruck, entsprechend $14,916 \%$ Stickstoff.

$0,2788 \mathrm{~g}$ Substanz wurden mit $0,5 \mathrm{~g}$ Natriumcarbonat und wenig Salpeter über dem Spiritusbrenner geschmolzen, die Schmelze war bis auf einen geringen Rückstand in Wasser löslich. 2/5 der Lösung, zur Schwefelbestimmung verwendet, gaben 0,0106 g reines Baryumsulfat oder 1,327\% Schwefel. Der Rest der Lösung wurde auf Chloride und nach längerem Erwärmen mit Salpetersäure auf dem Wasserbade auf Phosphate geprüft. Er enthielt nur Spuren von Chlor, Phosphorsäure fehlte.

Eisen und Kupfer waren nicht vorhanden.

Zur Bestimmung von präformirter Schwefelsäure, die, von schwefelsaurem Ammon herrührend, noch vorhanden sein konnte, wurden $0,1159 \mathrm{~g}$ Substanz in salzsaurer Lösung heiss mit Chlorbaryum gefällt. Das gewogene Baryumsulfat betrug 
$0,0062 \mathrm{~g}$ entspr. 1,838\% Schwefelsäureanhydrid. Auf Ammonsulfat berechnet, würde es eine Beimischung von $3,010 \%$ Ammonsulfat bedeuten; ich habe diese präformirte Schwefelsäure auch als solches in Rechnung gebracht, weil nach Schlösing's Methode durch Magnesiumoxyd eine kleine Menge von Ammoniak frei gemacht wurde.

Endlich gaben $0,1476 \mathrm{~g}$ Substanz $0,0013 \mathrm{~g}$ oder $0,88 \%$ Asche, in der Calcium, Magnesium und Schwefelsäure nachgewiesen wurden.

Nach Abzug der Asche und des verunreinigenden Ammonsulfates enthält also der blaue Farbstoff:

$$
\begin{aligned}
& \text { Kohlenstoff . . . 50,09\% } \\
& \text { Wasserstoff . . 6,82\% } \\
& \text { Stickstoff . . . 14,85\% } \\
& \text { Schwefel . . } 0,62 \% \\
& \text { Sauerstoff . . 27,62\% } \\
& 100,00 \%
\end{aligned}
$$

Ich habe in der ersten Mittheilung die Vermuthung ausgesprochen, dass der blaue Farbstoff, der das prächtige Hochzeitskleid des Crenilabrus pavo bedingt, ein Eiweisskörper sei, und glaube durch die Analyse und die weiter mitzutheilenden Eigenschaften des Farbstoffes die Berechtigung dieser Annahme gestützt zu haben.

Die wässerige Lösung ist nicht fadenziehend, sie schäumt beim Schütteln mit Luft, reagirt neutral auf Lakmuspapier. Wie durch schwefelsaures Ammon kann durch Sättigung seiner wässerigen Lösung mit Magnesiumsulfat und mit Chlorammon der Farbstoff gefällt werden. Beide Fällungen sind aber nicht vollständig, der Farbstoff verändert sich ferner, die Lösung über dem Niederschlage war grün. Bleibt der durch Ammonsulfat gefällte Niederschlag längere Zeit mit einer concentrirteren Ammonsulfatlösung in Berührung, so erweist er sich schwerer löslich als vorher. Durch Chlorcalcium bei Gegenwart von Kalkwasser entsteht eine vollständige Fällung, aber mit rascher Verfärbung ins Gelbgrüne. Alkohol fällt einen grünen Niederschlag, der bei längerer Alkoholeinwirkung un- 
löslich ist, Aceton in reichlichem Ueberschusse fällt, ohne zu verändern.

Die mit wenig Essigsäure angesäuerte wässerige Lösung des Farbstoffes wird nach Zusatz von etwas Salz durch Gerbsäure wie durch Ferrocyankalium vollständig gefällt. Bei der letzteren Probe entsteht Anfangs nur eine Trübung, die in einigen Stunden sich bis zur vollständigen Ausfällung vermehrt.

Beim Kochen der mit wenig Essigsäure und etwas Chlornatrium versetzten Lösung wird eine hellgrüne Flüssigkeit erhalten, es entsteht kein Niederschlag.

Salpetersäure gibt eine prachtvoll rothviolette, aber vergängliche Färbung; beim Kochen wird die Lösung gelb; durch darauffolgenden Laugenzusatz schön orange.

Millon's Reaction gibt eine geringe Braunfärbung, aber keine Rothfärbung.

Eine Probe, in Kalilauge gelöst, wurde hellgrün, mit einer Spur Kupfervitriollösung trat die Biuretreaction mit fast rein blauer Farbe auf; war die Farbstofflösung mit Lauge gekocht worden, so gab die Biuretprobe einen mehr violetten Ton.

Mit alkalischer Bleilösung gekocht, entstand eine geringe Bräunung.

Die Reactionen mit Alkalien und Säuren wurden mit dem reinen Präparate analog, wie in der ersten Mittheilung beschrieben, erhalten. Fixe Laugen, wie Ammoniak, brachten aber in der Lösung keine Niederschläge hervor. Beim Kochen mit Salzsäure und wenig chlorsaurem Kalium tritt anfangs die gleiche Purpurfarbe auf, wie sie durch Salpetersäure entsteht. Die nach kurzer Chlorentwicklung entfärbte Lösung wurde abgedampft, sie gab mit Ammoniak eine Braunfärbung, hierauf, mit Lauge versetzt, wurde sie orangegelb.

Bei der Fäulniss tritt starker Indolgeruch auf. Ueber die rasche Zersetzbarkeit durch Pepsin-Salzsäure wurde schon in der ersten Mittheilung berichtet.

Wird das Präparat kurze Zeit mit Salzsäure gekocht, so färbt sich die Lösung gelbgrün, und beim Neutralisiren mit kohlensaurem Natron entsteht ein Eiweissniederschlag. Nach 1/4 stündigem Kochen mit Salzsäure im Wasserbade wurde 
eine Probe mit Fehling'scher Lösung geprüft, es entstand eine minimale Menge von Kupferoxydul; erst nach 12stündigem Stehenlassen konnte dieser leichte Belag constatirt werden; es muss noch dahingestellt bleiben, ob diese Reduction der Substanz selbst oder vielleicht einer geringen, doch nicht entfernten Mucinbeimengung zukommt.

Wird mit verdünnter Salzsäure längere Zeit gekocht, oder eine etwa 20\% ige Säure zum Kochen verwendet, so folgt der fast vollständigen Entfärbung eine intensiv indigoblaue Färbung, die an Intensität die ursprüngliche blaue Farbe übertrifft. Ihr Spectrum besteht aus zwei recht scharfen Streifen, die neben einander etwa dieselbe Stelle einnehmen, an welcher der breite Streifen des käuflichen Indigocarmins zu bemerken ist.

Diese Färbung ist recht beständig, erst nach mehrstündigem Kochen mit 20\% iger Salzsäure entfärbt sich die Flüssigkeit unter Abscheidung eines blauschwarzen Niederschlages, der beim Stehen an der Luft seine Farbe in die eines sogenannten Melanins ändert. Die blaue Farbe geht nicht in Chloroform über.

Da die Untersuchung dieses Veränderungsproductes möglicher Weise Aufschluss darüber bringen kann, ob hier ein complicirter Eiweisskörper vorliegt, will ich versuchen, sobald die Beschaffung frischen Materiales gelingt, diesen Farbstoff weiter zu charakterisiren.

Ich hatte an der K. K. zoologischen Station in Triest Gelegenheit, da die Munificenz des hohen K. K. Unterrichtsministeriums mir die Beschaffung kostspieligeren Arbeitsmateriales ermöglichte, auch die Farbstoffe anderer Labriden, vorwiegend Labrus turdus, zu untersuchen. Der schwarzblaue Farbstoff dieses Fisches ist gegen Reagentienwirkung ziemlich beständig und scheint dem blauen Crenilabrusfarbstoff nicht nahe zu stehen. Dagegen dürfte der blaue Farbstoff des Crenilabrus mediterraneus der gleiche Körper sein, wie der beschriebene Farbstoff.

Es dürfte von biologischem Interesse sein, festzustellen, ob dieser Eiweisskörper wohl keine andere Function zu erfüllen hat, als die der intensiven Färbung des Fisches. 
Brought to you by | University of Manc Authenticated'

Download Date | 6/5/15 6:21 PN 